\title{
High birth weights in prewar Faroe Islands
}

\author{
S F Olsen, D N Beck, R Kollslíđ, R W Rasmussen
}

Birth weights in the Faroe Islands are among the highest in the world. ${ }^{1}$ During the 1980 s, infants born there had 200 grams higher mean birth weight than their Danish peers. ${ }^{1}$ Half of this difference could be attributed to a longer gestation (four days on average), half to a higher fetal growth rate. ${ }^{2} \mathrm{~A}$ high intake of seafood has been suggested to be a possible cause of this pattern. ${ }^{2}$ The findings of four days longer mean gestation and 100 grams higher mean birth weight in Danish women who received fish oil during pregnancy only partially corroborated this hypothesis, ${ }^{3}$ as no effect was detected on fetal growth. However, several observational studies have exhibited direct associations between fetal growth rate and fish intake, ${ }^{4}$ and this suggests that factors in seafood other than the oily part might play a part. ${ }^{4}$

We hypothesised that if the cause(s) of the higher birth weights in the Faroes indeed are to be found in the traditional Faroese life style, we would find even higher birth weights before the second world war than today, because the way of life there changed dramatically after the war towards that of other Western societies.

\section{Population, methods, and results}

We extracted all available information recorded in midwife protocols during the period 1927 1937. Coverage was $94 \%$, as judged from official birth statistics. Mean birth weight was 3765 grams $(\mathrm{SD}=671, \mathrm{n}=6379)$. Restriction to a period with 99\% coverage, 1932-1937, resulted in a very similar estimate, 3762 grams. The 19 midwives who kept the protocols during 1927-1937 differed in measuring or recording practice(s) as appeared from their rounding off practice. However, stratification according to this factor also resulted in very similar estimates of the mean: for midwives who regularly recorded to the nearest 25 grams or less, the mean was 3745 grams $(n=613)$, whereas for those who regularly recorded to the nearest 50, 100, 250 and 500 grams the means were $3788(n=1051), 3724 \quad(n=971), 3782$ $(n=2898)$, and 3738 grams $(n=804)$, respectively. Restriction to infants explicitly stated to be born alive resulted in a mean of 3783 grams (SD 639, $n=6054$ ), which could be compared to the corresponding figure for the period 1969-1981, 3610 grams $(S D=607, n=10062) .{ }^{1}$ The study has been approved by the Scientific Ethical Committee of the Faroe Islands.

\section{Comment}

Mean birth weight was estimated to be 172 grams higher during 1927-1937 than half a century later. This was despite the fact that the study period was characterised by poverty and severe economic depression. ${ }^{5}$ It seems unlikely that this difference can be explained by selection bias or changes over time in recording or measuring practices. The proportion of women smoking in pregnancy is probably to have been lower than today's figure in the Faroes, which is around $30 \%$; however, even if the proportion were $0 \%$ in the earlier period, this factor would only account for a fraction of the observed decline in mean birth weight. The findings are therefore compatible with the hypothesis that particular factors in the traditional Faroese life style increase birth weight.

Funding: Føroya Landsstýri, Danmarks Grundforskningsfond, Sygekassernes Helsefond, and Nordisk Ministerråd.

Conflicts of interests: none.

1 Olsen SF, Joensen HD. High liveborn birth weights in the Faroes: a comparison between birth weights in the Faroes and in Denmark. $f$ Epidemiol Community Health 1985;39:27-32.

2 Olsen SF, Hansen HS, Sorensen TI, et al. Intake of marine at, rich in (n-3)-polyunsaturated fatty acids, may increase birthweight by prolonging gestation. Lancet 1986;ii:367-9.

3 Olsen SF, Sorensen JD, Secher NJ, et al. Randomised controlled trial of effect of fish-oil supplementation on pregnancy duration. Lancet 1992;339:1003-7.

4 Olsen SF. Further on the association between retarded foetal growth and adult cardiovascular disease. Could low intake of marine diets be a common cause? 7 Clin Epidemiol 1994;47:565-9.

5 Gudiónsson SV. Ernceringsekspeditionen til Farøerne 1936 1937 (The Nutrtion Expedition to the Faroe Islands 19361937). Copenhagen: Nyt Nordisk Forlag, 1940. 